\title{
Postcranial heterochrony, modularity, integration and disparity in the prenatal ossification in bats (Chiroptera)
}

\author{
Camilo López-Aguirre ${ }^{1 *}$ (D), Suzanne J. Hand ${ }^{1}$, Daisuke Koyabu ${ }^{2,3}$, Nguyen Truong Son ${ }^{4,5}$ and Laura A. B. Wilson ${ }^{1}$
}

\begin{abstract}
Background: Self-powered flight is one of the most energy-intensive types of locomotion found in vertebrates. It is also associated with a range of extreme morpho-physiological adaptations that evolved independently in three different vertebrate groups. Considering that development acts as a bridge between the genotype and phenotype on which selection acts, studying the ossification of the postcranium can potentially illuminate our understanding of bat flight evolution. However, the ontogenetic basis of vertebrate flight remains largely understudied. Advances in quantitative analysis of sequence heterochrony and morphogenetic growth have created novel approaches to study the developmental basis of diversification and the evolvability of skeletal morphogenesis.

Assessing the presence of ontogenetic disparity, integration and modularity from an evolutionary approach allows assessing whether flight may have resulted in evolutionary differences in the magnitude and mode of development in bats.

Results: We quantitatively compared the prenatal ossification of the postcranium (24 bones) between bats (14 species), non-volant mammals (11 species) and birds (14 species), combining for the first time prenatal sequence heterochrony and developmental growth data. Sequence heterochrony was found across groups, showing that bat postcranial development shares patterns found in other flying vertebrates but also those in nonvolant mammals. In bats, modularity was found as an axial-appendicular partition, resembling a mammalian pattern of developmental modularity and suggesting flight did not repattern prenatal postcranial covariance in bats.

Conclusions: Combining prenatal data from 14 bat species, this study represents the most comprehensive quantitative analysis of chiropteran ossification to date. Heterochrony between the wing and leg in bats could reflect functional needs of the newborn, rather than ecological aspects of the adult. Bats share similarities with birds in the development of structures involved in flight (i.e. handwing and sternum), suggesting that flight altriciality and early ossification of pedal phalanges and sternum are common across flying vertebrates. These results indicate that the developmental modularity found in bats facilitates intramodular phenotypic diversification of the skeleton. Integration and disparity increased across developmental time in bats. We also found a delay in the ossification of highly adaptable and evolvable regions (e.g. handwing and sternum) that are directly associated with flight performance.
\end{abstract}

Keywords: Sequence heterochrony, Postcranial development, Prenatal growth, Modularity, Integration, Ontogeny

\footnotetext{
* Correspondence: c.lopez-aguirre@unsw.edu.au

${ }^{1}$ PANGEA Research Centre, School of Biological, Earth \& Environmental

Sciences, University of New South Wales, Sydney, NSW 2052, Australia

Full list of author information is available at the end of the article
}

(c) The Author(s). 2019 Open Access This article is distributed under the terms of the Creative Commons Attribution 4.0 International License (http://creativecommons.org/licenses/by/4.0/), which permits unrestricted use, distribution, and reproduction in any medium, provided you give appropriate credit to the original author(s) and the source, provide a link to the Creative Commons license, and indicate if changes were made. The Creative Commons Public Domain Dedication waiver (http://creativecommons.org/publicdomain/zero/1.0/) applies to the data made available in this article, unless otherwise stated. 


\section{Background}

Pterosaurs, birds and bats are the only vertebrates capable of self-powered flight (herein refered to as flight, [1]). However, the phylogenetic relationships between these groups and their position in the evolutionary history of vertebrates have shown that this feature evolved in each group independently, as a result of convergent evolution [1, 2]. Historically, the convergent evolution of vertebrate flight was asynchronous, with pterosaurs evolving flight first ( $\approx 240$ Mya), followed by birds $(\approx 140$ Mya), and bats ( $\approx 60$ Mya) [3-5]. Flight was a key innovation that provided a major ecological opportunity for these groups, allowing them to diversify into a vast range of previously empty niches [6]. As a result, both birds and bats are some of the most speciose groups of living vertebrates. It is estimated that pterosaurs were also abundant and diverse before their extinction, with over 160 fossil species described [7].

It has been suggested that all three groups share some morphological and physiological adaptations in body regions that are vital for the kinematics of flight [8]. Reduction of cortical bone thickness [9], increased bone density [8], morphological changes in the pectoral girdle [10], and elongation of forelimb bones are some of the adaptations that these groups share [11]. It has also been found that all three groups have relatively small genomes when compared to their respective close relatives [3], suggesting that constricted genome sizes has been evolutionarily correlated with the evolution of self-powered flight in vertebrates $[3,12]$.

The relatively abundant fossil record of pterosaurs and birds has facilitated the study of the evolution of flight in these groups. Bat flight evolution, on the other hand, has been comparably more difficult to study due to the incompleteness of the fossil record, limiting the scope for research [13-22]. Studying how the development of organisms reflects their evolutionary history [23-28], represents an alternative to assess the extent of interspecific variation in postcranial morphology over the course of ontogeny, data that could provide a baseline for further study into the evolution of mammalian flight $[22,29]$.

Based on previous studies that used ossification to study morphogenesis, we now know that the development of specific traits is not homogenous across taxa that share those features [30-32]. This has been demonstrated for both analogous and homologous traits [33]. Comparisons of ossification sequences have shown that the interaction between ontogeny and ecology has a domino effect on the modification and specialisation of the mammalian skeleton $[34,35]$. Nevertheless, previous studies have suggested that it may not always be possible to differentiate between functional and phylogenetic developmental fluctuations [36]. The delimitation between ontogenetic changes reflecting a phylogenetic signal and changes reflecting ecomorphological adaptations is not clear when analysing developmental sequences without testing a specific hypothesis [36].

There are two general approaches to study changes in morphology during development: sequence heterochrony and developmental growth analyses [37]. Sequence heterochrony analyses document variations in the timing and order in which a group of traits starts developing, permitting the study of developmental events that are not explicitly characterized by size or shape [37]. Developmental growth refers to differences in the timing of growth onset, and growth rate that different traits experience during the development of an individual [37]. Studying sequence heterochrony has been particularly useful to elucidate developmental differences in patterns of ossification in a wide range of vertebrate taxa [35, 37-41]. Among vertebrates, mammals exhibit the widest range of skeletal specialisations for different locomotor and feeding strategies [23-25, 42]. As a result, mammals have successfully adapted to more ecosystems than any other vertebrate group $[6,14,43]$. Sequence heterochrony studies of skeletal ossification in mammals have suggested an ontogenetic basis for the functional adaptability of the postcranium [23, 24, 44, 45]. Sequence heterochrony in mammals has also been linked to both phylogeny and life history [36, 44, 45].

Developmental growth studies have helped to elucidate evolutionary changes in ontogenetic trajectories across lineages [23, 24, 33, 35, 46]. By focusing on the morphological changes across the development of a structure, it is possible to recreate the relationship between shape and size and how it responds to ecological, genetic and ontogenetic constrains [47-50]. This principle has been applied to the evolutionary history of different taxa, reconstructing ancestral states and historical divergences and diversifications, providing a developmental perspective to the study of evolution [51-54].

Prenatal and postnatal development have been found to be drastically dissimilar processes for some species [55-58], experiencing different selective pressures [56, 58], and resulting in differential effects on morphological disparity at adulthood [34, 48, 56, 58]. A prenatal developmental basis has been suggested for the phenotypic diversity in some mammal species, proposing that prenatal development shows more variability as it does not experience strong environmental changes [54, 55]. Moreover, a link between altriciality and the capacity of a system to evolve (i.e. evolvability; [26]) has been proposed, in which incomplete development at birth and extended developmental times have been hypothesised to facilitate adaptability [56, 58].

Another aspect of mammalian evolution that has been increasingly studied is how the interaction between morphological disparity and integration shape the phenotypic 
evolution of a clade [47, 59-61]. Morphological disparity refers to the phenotypic variability within a set of individuals, whereas morphological integration indicates a correlation in the morphological variation of a set of traits $[62,63]$. Recent quantitative studies have examined the role that the interaction between disparity and integration could play in the evolutionary history of a group, leading to two, mutually-exclusive hypotheses tractable to testing: 1) high levels of integration restrains disparity, canalising all phenotypes to a similar state [59], or 2) high levels of integration create an "evolutionary buffer" that facilitates disparity, leading to phenotypic diversification [59]. These two hypotheses help to define the range of possible forms that the disparity-integration interaction can take in biological systems. Furthermore, integration can create groups of traits that show high within-group correlations, but that are weakly connected and therefore relatively independent from other groups (i.e. modularity; [63-65]). Consequently, one could expect that modularity would vary in its configuration as integration of the entire system is higher, as all traits are strongly correlated.

Despite increased interest in the morphological development and ontogeny of mammals [22, 23, 38, 47, 66, 67], many questions regarding the ontogenetic basis of modern phenotypic diversity remain unanswered. Bats are an excellent example of ecomorphological diversity within Mammalia, having a wide range of dietary specialisations [68], and exhibiting a range of locomotor strategies [69]. Bats show a unique, highly derived postcranial body plan adapted to flight (e.g. elongated forelimbs, reduced bone cortical thickness, specialised pectoral girdle morphology) [8-11], but different bat species are also capable of walking and in some extreme cases swimming [70-72]. To date, few studies have focused on quantifying and interpreting heterochrony of the postcranium in bats [73, 74]. Koyabu and Son [36] showed that bats have accelerated ossification of the phalanges of the hindlimbs and thumb during prenatal development, and suggested that this pattern could be a functional response to the need to continuously attach to their mothers and to the substrate of their roosts. This is particularly relevant in bats because newborns are incapable of flying for several weeks or up to several months after birth [36]. Given that vertebrate flight is polyphyletic, it is possible that the processes underlying postcranial development in bats converged with those of other flying vertebrates. Consequently, bat postcranial ossification could diverge from a more phylogenetically constrained mammalian development to a more functionally convergent flying vertebrate development. However, our understanding of the developmental basis of vertebrate flight remains limited.

Combining sequence heterochrony and metric growth data, this study compared the prenatal ossification of the postcranium in bats, birds and non-volant mammals, evaluating whether flight may have shaped the magnitude and mode of postcranial development in bats compared to non-volant mammals and birds. We used the most comprehensive sampling of prenatal bats to date. We quantify the levels of disparity and integration across bones during ossification, to assess whether integration restrains or promotes disparity during the development of bats. Considering that flight and the associated morphological specialisations are exclusive to bats among mammals, we expect to find a shift in the postcranial development of bats compared to non-volant mammals, showing some similarities with other flying vertebrates. Also, based on the embryological origin and functional differences of different regions of the postcranium, we expect to find evidence of ontogenetic modularity. As a result, we expect a positive correspondence between magnitudes of disparity and integration within each module, as well as differences in levels of disparity and integration between modules.

\section{Methods \\ Data collection}

To study prenatal postcranial ossification in bats, 66 specimens representing developmental series of 11 bat species (Aselliscus dongbacana, A. stoliczkanus, Cynopterus sphinx, Hesperoptenus blanfordi, Hipposideros larvatus, Kerivoula hardwickii, Miniopterus schreibersii, Myotis sp., Rhinolophus pearsoni, R. pusillus, R. thomasi) were sampled, comprising five families and members from both chiropteran suborders Yinpterochiroptera and Yangochiroptera (Table 1). Specimens were collected and prepared in Vietnam for a study of sequence heterochrony in bats [36], and stored in 70\% ethanol. Grey scale images of specimens were acquired using a microfocal X-ray CT system at the University Museum, University of Tokyo (TXS225-ACTIS, TESCO, Tokyo) with $70 \mathrm{kV}$ source voltage and $\mu 114 \mathrm{~A}$ source currents at a resolution of $36 \mu \mathrm{m}$ (Fig. 1). Segmentation of the skeleton from other tissues was performed using the thresholding tool in MIMICS v. 20 software (Materialise NV), using the bone $(\mathrm{CT})$ predefined set as a basis. Finer thresholding to separate CT-values of osseous and non-osseous structures followed the Half Maximum Height method (HMH) [75]. This technique did not allow us to reconstruct cartilaginous tissue during the growth of the skeleton, limiting our capacity to describe the growth of non-osseous tissue in the bone.

Ossification sequence data of 24 postcranial elements were recorded by analysing the $3 \mathrm{D}$ virtual models of the postcranial skeleton using MIMICS v. 20 software (Materialise NV). Raw models of scanned specimens were thresholded to generate the virtual models of the postcranial skeleton (Fig. 1). Ossification sequences for three additional species were 
Table 1 List of mammal and bird species analysed in this study

\begin{tabular}{|c|c|c|c|c|}
\hline Class & Order & Family & Species & Source \\
\hline \multirow[t]{25}{*}{ Mammalia } & \multirow[t]{14}{*}{ Chiroptera } & \multirow[t]{3}{*}{ Hipposideridae } & Aselliscus dongbacana & This study $(n=14)$ \\
\hline & & & Aselliscus stoliczkanus & This study $(n=16)$ \\
\hline & & & Hipposideros larvatus & This study $(n=4)$ \\
\hline & & \multirow[t]{2}{*}{ Pteropodidae } & Cynopterus sphinx & This study $(n=4)$ \\
\hline & & & Rousettus amplexicaudatus & {$[23]$} \\
\hline & & \multirow[t]{3}{*}{ Rhinolophidae } & Rhinolophus pearsoni & This study $(n=1)$ \\
\hline & & & Rhinolophus pusillus & This study $(n=1)$ \\
\hline & & & Rhinolophus thomasi & This study $(n=10)$ \\
\hline & & \multirow[t]{5}{*}{ Vespertilionidae } & Hesperoptenus blanfordi & This study $(n=5)$ \\
\hline & & & Kerivoula hardwickii & This study $(n=7)$ \\
\hline & & & Myotis sp. & This study $(n=2)$ \\
\hline & & & Myotis ater & {$[36]$} \\
\hline & & & Myotis lucifugus & {$[36]$} \\
\hline & & Miniopteridae & Miniopterus schreibersii & This study $(n=2)$ \\
\hline & \multirow[t]{7}{*}{ Rodentia } & \multirow[t]{4}{*}{ Muridae } & Rattus norvegicus & {$[36]$} \\
\hline & & & Meriones unguiculatus & {$[36]$} \\
\hline & & & Mus musculus & {$[36]$} \\
\hline & & & Rhabdomys pumilio & {$[36]$} \\
\hline & & \multirow[t]{2}{*}{ Cricetidae } & Peromyscus melanophrys & {$[36]$} \\
\hline & & & Mesocricetus auratus & {$[36]$} \\
\hline & & Octodontidae & Octodon degus & {$[36]$} \\
\hline & \multirow[t]{2}{*}{ Eulipotyphla } & Soricidae & Cryptotis parva & {$[36]$} \\
\hline & & Talpidae & Talpa europaea & {$[36]$} \\
\hline & \multirow[t]{2}{*}{ Cetartiodactyla } & Bovidae & Bos taurus & {$[36]$} \\
\hline & & Suidae & Sus scrofa & {$[36]$} \\
\hline \multirow[t]{14}{*}{ Aves } & \multirow[t]{3}{*}{ Galliformes } & \multirow[t]{3}{*}{ Phasianidae } & Meleagris gallopavo & {$[77]$} \\
\hline & & & Coturnix coturnix & {$[77]$} \\
\hline & & & Gallus gallus & {$[77]$} \\
\hline & Struthioniformes & Struthionidae & Struthio sp. & {$[77]$} \\
\hline & Casuariiformes & Casuariidae & Dromaius novaehollandiae & {$[77]$} \\
\hline & \multirow[t]{3}{*}{ Anseriformes } & \multirow[t]{3}{*}{ Anatidae } & Somateria mollissima & {$[77]$} \\
\hline & & & Anas platyrhynchos & {$[77]$} \\
\hline & & & Cairina moschata & {$[77]$} \\
\hline & Pelecaniformes & Phalacrocoracidae & Phalacrocorax auritus & {$[77]$} \\
\hline & \multirow[t]{5}{*}{ Charadriiformes } & \multirow[t]{4}{*}{ Laridae } & Sterna hirundo & {$[77]$} \\
\hline & & & Larus ridibundus & {$[77]$} \\
\hline & & & Larus argentatus & {$[77]$} \\
\hline & & & Larus canus & {$[77]$} \\
\hline & & Stercorariidae & Stercorarius skua & {$[77]$} \\
\hline
\end{tabular}

compiled from previous studies (Additional file 1: Figure S1): Rousettus amplexicaudatus [23], Myotis ater [36] and M. lucifugus [76]. Prenatal ossification sequences of 11 non-volant mammal species and 14 bird species were consolidated based on previously published studies [36, 77]. Our sample included three orders, eight families of non-volant mammals, and six orders and seven families of birds. 


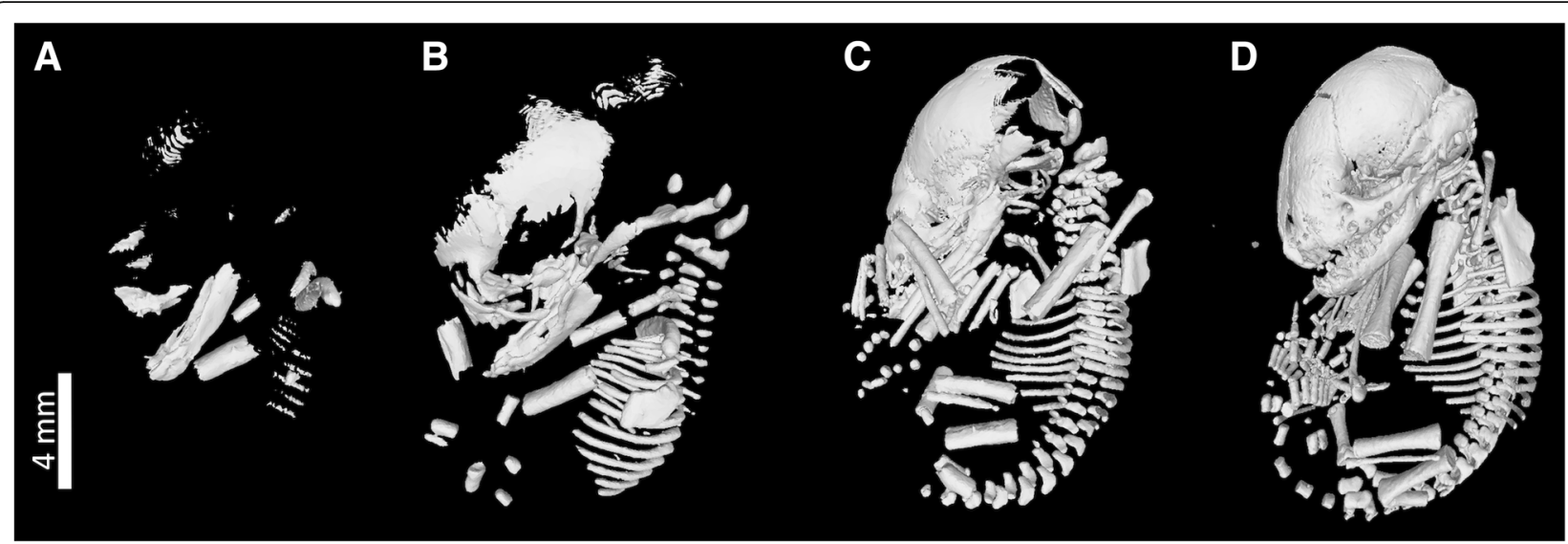

Fig. $13 \mathrm{D}$ virtual models of ontogenetic series of $H$. blanfordi, representing the samples from which raw measurements were taken from postcranial elements. Specimens represent different developmental stages: Stage 1 (a), stage $3(\mathbf{b})$, stage 8 (c), and stage 10 (d). Stage 1 is characterised by ossification of the humerus, clavicle and ribs; stage 3 by ossification of ilium and tibia; stage 8 by ossification of manual phalanges, and stage 10 by ossification of carpals

\section{Sequence heterochrony}

For each specimen, the ossification level of each bone was codified as one of three categories: unossified, ossification onset, or partly ossified. To consolidate the ossification sequence of each species, we followed a modified absolute rank $r$ standardisation implemented in previous studies [23, 24, 34, 78, 79]. The traditional approach standardises the absolute rank $r$ by the maximum number of ranks, which has been shown to result in high variability in the relative rank of the first bones to ossify [36]. To address this, the relative rank of each species was scaled from 0 (i.e. earliest ossification event) to 1 (i.e. latest ossification event), removing possible interspecific differences in the maximum rank number (see [74]). Only species with well-resolved developmental series (i.e. $\geq 4$ ranks) were included in further analyses.

To compare the prenatal ossification sequences of bats with both non-volant mammals and flying vertebrates, we controlled for anatomical differences between birds and mammals, standardising a unique anatomical nomenclature of homologous structures. Consequently, the avian furcula was matched with the mammalian clavicle. Given the complex structure of the avian synsacrum, the ossification of the avian sacral vertebrae was paired with the lumbar and sacral mammalian vertebrae. Finally, in order to visualise developmental differences across groups, we performed a Principal Component Analysis (PCA) of the ossification sequences of all 39 species pooled as bats, birds and non-volant mammals. All analyses were performed with PAST 3.18 [80].

\section{Metric growth}

$3 \mathrm{D}$ virtual reconstructions of the postcranial skeleton of all 66 specimens were used to collect a total of 25 linear measurements (Table 2). Measurements were obtained from 3D renderings of the virtual models using the measure distance tool in MIMICS v. 20 software (Materialise NV). Measurements were logarithmically transformed prior to analysis. Missing values were replaced using linear interpolation with the na.approx function of the R package $z o o$ version 1.8 [81]. Mean values of each measurement were used to create a single developmental growth sequence for each species.

For bone categories representing more than a single bone (e.g. ribs and vertebrae) we always measured the same bone, usually being the one first to ossify within the category (see Table 2 for specifications). To control possible bilateral asymmetry due to developmental instability in our data, we measured bones only on the left side for all specimens. Since all analyses were performed at ordinal level, all species were included in further analysis, including $R$. pearsoni and $R$. pusillus that were represented only by one individual each.

\section{Developmental modularity}

To assess the presence of correlation between prenatal ossification ranks we conducted a neighbour-joining clustering analysis based on the scaled ossification ranks of each bone, bootstrapping each node with 10,000 permutations [36]. Kendall's $\tau$ was used to test modularity in prenatal ossification ranks for bats, birds and non-volant mammals separately, performing pairwise comparisons between all 24 bones based on their relative ossification ranks. Following previous studies [59], seven different functional and anatomical modularity hypotheses were tested: 1) vertebral column, 2) axial skeleton, 3) appendicular skeleton, 4) armwing, 5) handwing, 6) forelimb and 7) hindlimb. Additionally, to explore the ontogenetic basis of modularity, we developed two new hypotheses based on the embryological origin of the 
Table 2 Description of 25 linear measurements of the postcranial skeleton of bat fetuses used in this study

\begin{tabular}{|c|c|c|c|}
\hline Measurement & Acronym & Description & Module \\
\hline Crown-Rump Length & CRL & Length from the top of the head to bottom of torso & - \\
\hline Humeral Length & $\mathrm{HL}$ & Left humerus length & $3,4,6,8$ \\
\hline Clavicular length & $\mathrm{CL}$ & Left clavicle length & $2,6,8$ \\
\hline Scapular length & SL & Left scapula length & $2,6,8$ \\
\hline Femoral length & $\mathrm{FL}$ & Left femur length & $3,7,8$ \\
\hline Rib length & RiL & First left rib length & 2,9 \\
\hline Tibial length & $\mathrm{TL}$ & Left tibia length & $3,7,8$ \\
\hline Fibular length & FiL & Left fibula length & $3,7,8$ \\
\hline Radial length & RL & Left radius length & $3,4,6,8$ \\
\hline Ulnar length & UL & Left ulna length & $3,4,6,8$ \\
\hline Sternum length & StL & Sternum length & 2,8 \\
\hline Manual phalange length & MPL & Proximal phalange of second digit of left forelimb & $3,5,6,8$ \\
\hline Pedal phalange length & PPL & Proximal phalange of first digit of left hindlimb & $3,7,8$ \\
\hline Metacarpal length & McL & Metacarpus of second digit of left forelimb & $3,5,6,8$ \\
\hline Metatarsal length & MtL & Metatarsal of first digit of left hindlimb & $3,7,8$ \\
\hline Tarsal length & TaL & Length of calcaneus of left hindlimb & $3,7,8$ \\
\hline Carpal length & CaL & Length of scaphoid of left forelimb & $3,5,6,8$ \\
\hline Cervical vertebral width & $\mathrm{CVL}$ & C1 vertebral width & $1,2,9$ \\
\hline Thoracic vertebral width & TVL & T1 vertebral width & $1,2,9$ \\
\hline Lumbar vertebral width & LVL & L1 vertebral width & $1,2,9$ \\
\hline Sacral vertebral width & SVL & S1 vertebral width & $1,2,9$ \\
\hline Caudal vertebral width & CavL & vertebral width of first caudal vertebra & $1,2,9$ \\
\hline Ilium length & IIL & Length from top of iliac crest to the edge of triradiate joint & $2,7,8$ \\
\hline Ischium length & IsL & Length from bottom of ramus to edge of triradiate joint & $2,7,8$ \\
\hline Pubis bone length & PuL & Length from bottom of ramus to edge of triradiate joint & $2,7,8$ \\
\hline
\end{tabular}

Numbers indicate the modularity hypotheses where each bone was included (see Table 3 for number coding)

bone: 8) abaxial skeleton or lateral plate mesoderm (LPM)-derived, and 9) primaxial skeleton or somite-derived (see Table 2 for specifications, [82-84]). All hypotheses were evaluated for Chiroptera, non-volant mammals and birds.

Finally, to visualise the similarities between bone growth patterns informed by the modules obtained in the two previous analyses, we performed a PCA grouping all 24 bones into the best supported modularity model. All analyses were performed with PAST 3.18 [80].

\section{Developmental disparity and integration}

Morphological integration was interpreted as the relative eigenvalue standard deviation (i.e. eigenvalue dispersion) of a PCA of all 24 bones for all 66 bat specimens. With this approach, high levels of dispersion mean that few eigenvectors account for a high proportion of variance, indicating strong integration [85]. Morphological disparity was measured as the statistical variance of the linear measurements of each bone. To test differences in disparity and integration between hypothetical developmental modules we averaged the values obtained for all bones within each module. Finally, to describe temporal shifts in disparity and integration across the prenatal development of Chiroptera, we staged all bat specimens based on criteria previously published for different bat species [86-90]. Since CS staging systems have not been developed for nine of the 11 species in the prenatal sample, specimens were classified into one of 10 developmental stages (1-10), based on the development of external features, bone ossification sequence and crown to rump length (CRL, Fig. 1). Linear Discriminant Function Analysis (LDA) was performed to statistically assess the accuracy of our staging system and visualise the spatial separation between the stages (Additional file 2 Figure S2). By combining both datasets we circumvent the issue of establishing discrete categories along a continuous morphometric dimension, informing our staging system with a discrete component of development. Generalised Linear Model (GLM) was used to test the correlation between integration and disparity across bones and developmental time and PCA to 
visualise the distance between species in the developmental space in PAST 3.18 [80].

The effect of uneven bat species representation across developmental stages on values of disparity and integration was assessed with Pearson's correlations. Also, Pearson's correlations were used to test whether the number of specimens per developmental stage influences values of disparity and integration. Uncertainty in the values of disparity and integration was assessed by estimating 95\% confidence intervals with 10,000 bootstrap replicates using the boot package version 1.3 in $\mathrm{R}$ [91].

\section{Results}

\section{Sequence heterochrony}

General patterns of sequence heterochrony were evident across the chiropteran skeleton. Bones of the stylopod (proximal section) and zeugopod of both limbs, and the pectoral girdle are the first ones to ossify, followed by bones of the autopod (distal section) of both limbs and all but the caudal vertebrae of the spinal column (Fig. 2). Carpals, caudal vertebrae, ischium and sternum are the last bones to ossify. Metatarsals and pedal phalanges showed the highest variance in their relative ranking, whereas the clavicle was invariably the first bone to ossify. Compared to the other groups, postcranial ossification sequence in bats have similarities with both non-volant mammals and birds (Fig. 2). Vertebral column ossification in bats is delayed compared to non-volant mammals and birds, showing a distinctive developmental process in this region unique to bats, a pattern also found for the ischium. In contrast, bats and non-volant mammals show an early ossification of the stylopod and zeugopod of both limbs, compared to birds. Bats and birds shared a delay in the ossification of the sternum, compared to non-volant mammals. All groups had a late ossification of the carpals.

PCA analysis revealed a clear differentiation between the prenatal ossification of the postcranium of mammals and birds, with bats and non-volant mammals occupying a single developmental space (Fig. 3). PC1 and PC2 combined explained $67.33 \%$ of the variation. Chiroptera's development showed the highest variability in our sample, occupying the largest space across PC1 and PC2. Negative values along PC1 (49.47\%) indicate delayed ossification of the caudal vertebrae, manual phalanges, pubis and ischium, whereas positive values indicate early ossification of clavicle, humerus and radius. PC2 $(17.86 \%)$ is associated with early ossification of the presacral vertebrae.

\section{Developmental growth}

In contrast to our results of sequence heterochrony in early-ossifying bones, the last bones to ossify were the ones with the shortest lengths across bat species (Additional file 3: Table S1). Such is the case for the sternum and the carpals, where for most species the

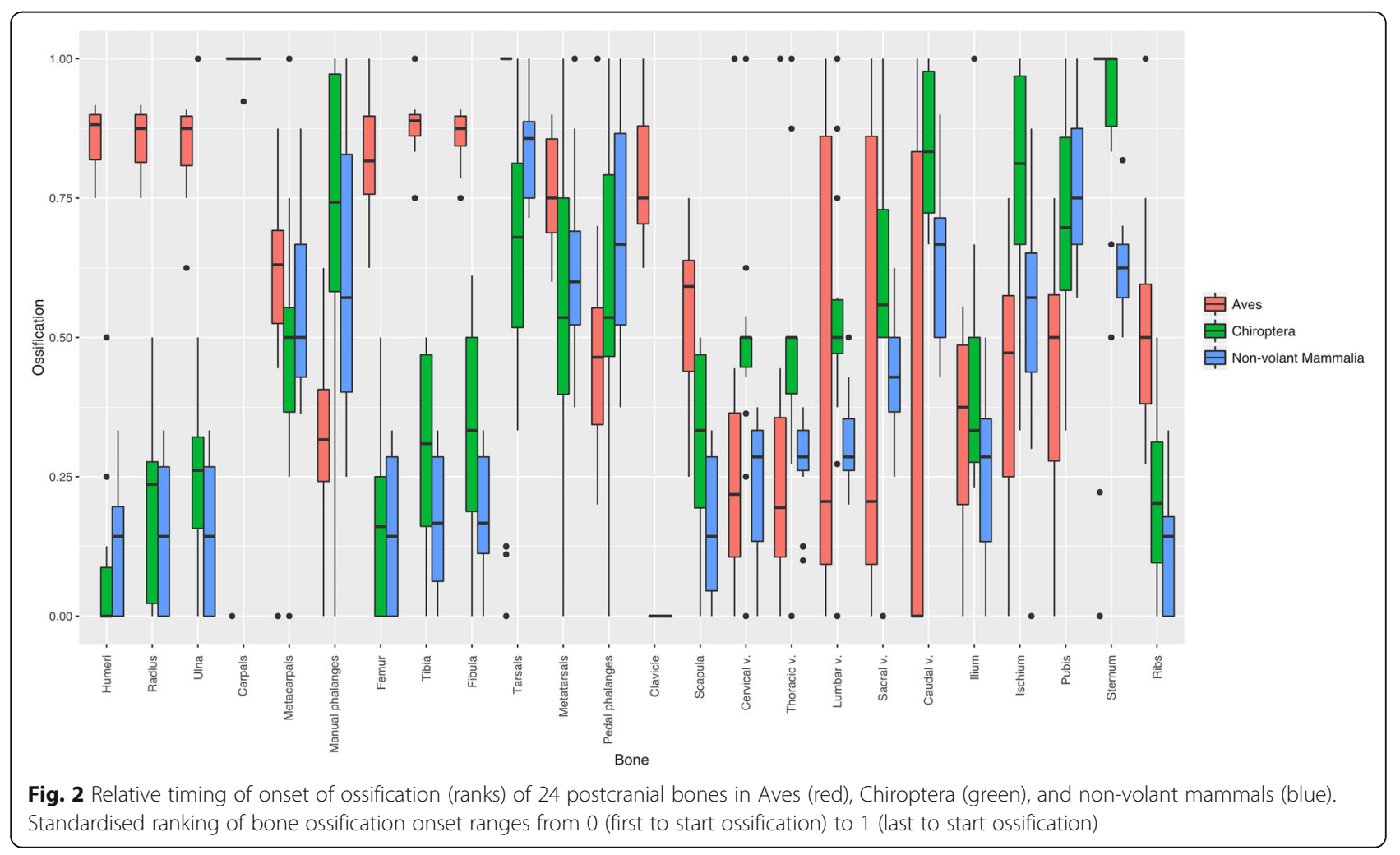




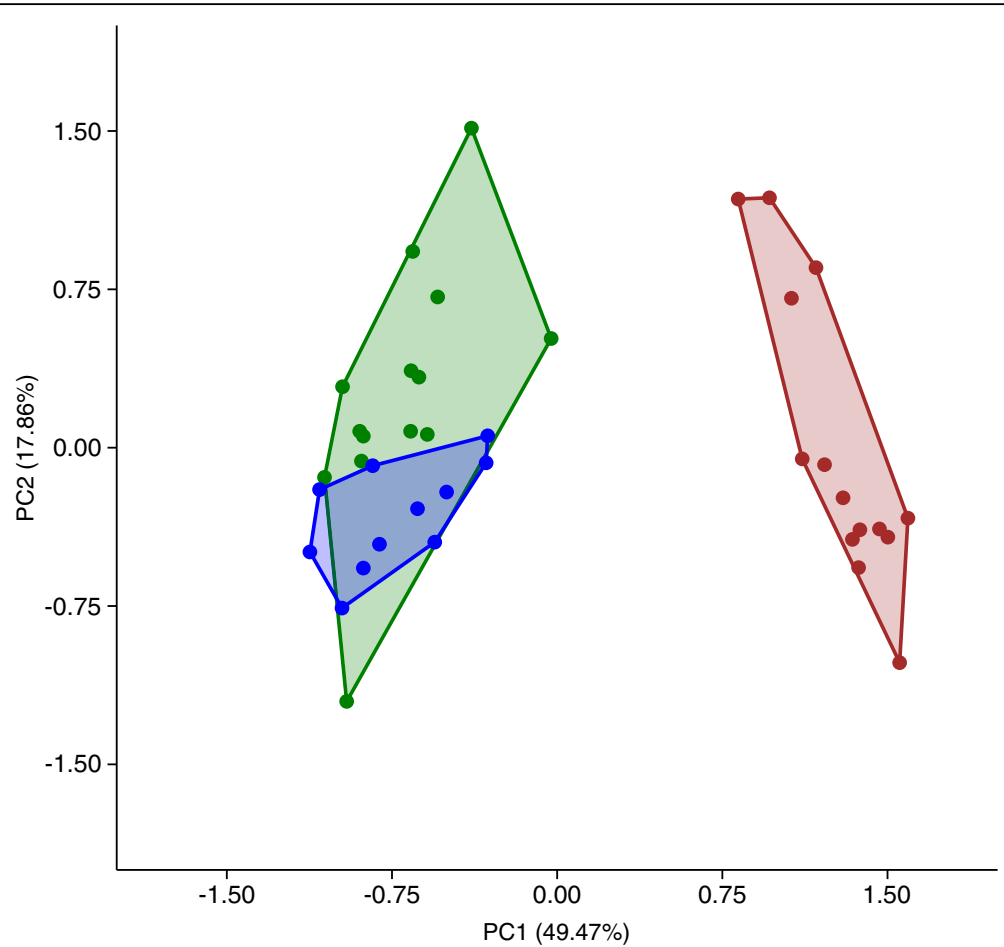

Fig. 3 Principal Component Analysis of of the ossification sequences of 24 postcranial bones (relative ranks from 0 to 1 ) in 39 vertebrate species analysed in this study. Species are plotted across PC1 (49.47\%) and PC2 (17.86\%), and are grouped as Aves (red), Chiroptera (green), and nonvolant mammals (blue)

adjusted ranks were frequently zero. Overall, CRL had the highest variance of all measurements, followed by UL and RL (see Table 2 for abbreviations). CaL and CavL showed the lowest variance, followed by TaL and StL. Regarding the limbs, measurements of the zeugopod showed the highest variance, whereas measurements of the autopod showed the lowest. With the exception of the cervical vertebrae, most of the sections of the spinal column had similar magnitudes of variance.

\section{Developmental modularity}

Permutated neighbour-joining cluster analysis revealed two well-defined clusters of bones in the postcranium, one comprising the stylopod and zeugopod of both limbs as well as both girdles and the ribcage, and the other comprising the autopod of both limbs and most of the spinal column (Fig. 4).

Of all nine modularity hypotheses tested with Kendall's $\tau$ across all birds, bats and non-volant mammals, six were statistically significant before Bonferroni correction (Table 3). Axial and appendicular modules were significant for all taxonomic groups, whereas the forelimb and hindlimb functional modules were significant only for Chiroptera and non-volant mammals. After Bonferroni correction, however, the appendicular and axial hypotheses were both significant for Chiroptera and non-volant mammals, whereas only the appendicular was significant for birds. The abaxial hypothesis was significant for both mammal groups only.

PCA results grouping linear measures of all 24 bones based on this axial-appendicular model showed a clear distinction between the two modules, with only four variables showing an overlap between both modules (Additional file 4: Figure S3).

\section{Disparity and integration}

Values of integration ranged from 0.011 to 0.458 across the postcranium (mean 0.088). Seven bones showed integration values higher than average, with metacarpals and pedal phalanges with the highest values $(0.458$ and 0.338 respectively; Fig. 5). Manual phalanges, tibia and fibula showed the lowest values $(<0.02$; Fig. 5). Disparity in bats ranged from 0.002 to 0.138 (mean 0.061), with the highest values found in the radius and fibula, and the lowest values in the carpals and the thoracic vertebrae. The appendicular module showed higher values of integration and disparity than the axial module, both higher than average ( 0.175 for disparity and 0.11 for integration), whereas both integration and disparity in the axial module were below average (0.075 and 0.07) (Fig. 6). Disparity was significantly different between modules, whereas integration was not (ANOVA, disparity: $P=<0.001, F_{(1,23)}=15.49$; integration: $0.333, F_{(1,23)}=$ 0.978). GLM did not reveal a significant association 


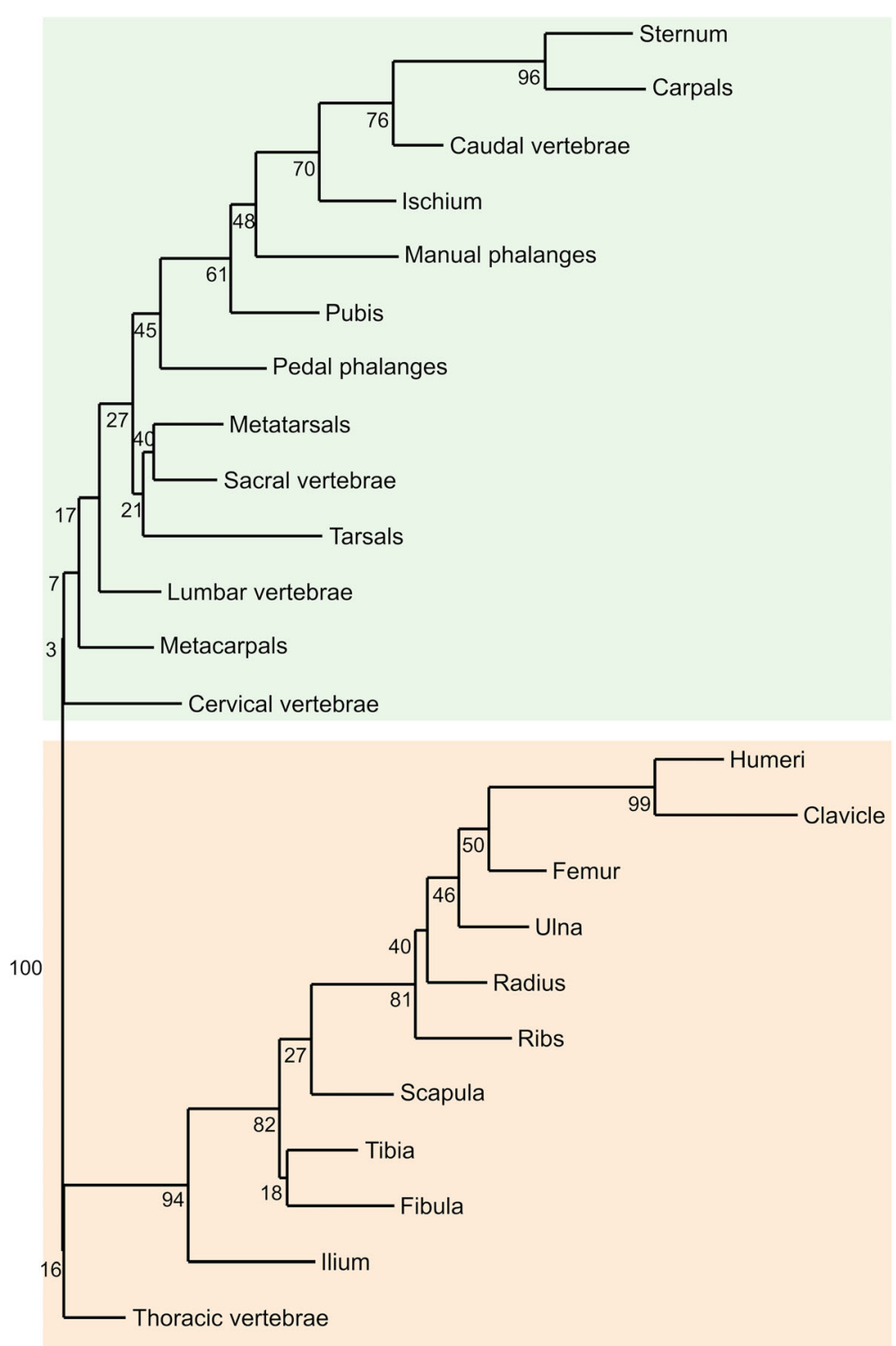

Fig. 4 Neighbour-joining clustering analysis of ossification sequence of 24 postcranial bones (relative ranks from 0 to 1 ) in bats. Colours represent the two best-supported groups. Numbers represent level of support at each node after 10,000 randomisations

between integration and disparity across bones $(P=0.832$, $\mathrm{R}^{2}=0.002$; Additional file 5: Figure S4). Our results of disparity and integration across developmental time show that both disparity and integration increase across time, but neither follows a clear temporal pattern (Fig. 7).

LDA showed that the staging system implemented for the bat specimens successfully separated developmental stages $(93.94 \%$ of specimens correctly classified, Additional file 2: Figure S2). Stages were characterised by a CRL range and ossification events specific to each stage (Additional file 6: Table S2). Disparity across developmental stages had a tendency to increase but neither linearly nor exponentially $\left(R^{2}=0.31\right.$ and 0.36$)$. Integration, on the other hand, reached its highest values in stages
6 and 10, but did not show a clear pattern of increase that fitted either a linear model or exponential curve $\left(R^{2}=0.26\right.$ and 0.06). Pearson's correlations showed non-significant relationships between disparity, integration and the number of specimens per stage (disparity: $\rho=0.103, P=0.775$; integration: $\rho=-0.19, P=0.584$; Additional file 7: Figure S5). Pearson's correlation also showed that differences in species sampling across stages had no effect in values of disparity and integration (disparity: $\rho=0.006, P=0.986$; integration: $\rho=-0.228, P=0.525)$. GLM showed that integration and disparity are not correlated across developmental time $\left(P=0.199, \mathrm{R}^{2}=0.196\right.$; Additional file 8: Figure S6). Bootstrapping revealed that all disparity and integration values (both across bones and developmental 
Table 3 Kendall's t results testing nine different modularity hypotheses of metric growth

\begin{tabular}{|c|c|c|c|}
\hline & Chiroptera & Aves & Non-volant mammals \\
\hline Vertebral column (1) & $0.2(0.8065)$ & $-0.111(1)$ & $0.738(0.129)$ \\
\hline Axial skeleton (2) & $0.879(<0.0001)^{*}$ & $0.576(0.1662)$ & $0.806(<0.0001)^{*}$ \\
\hline Appendicular skeleton (3) & $0.818(0.0002)^{*}$ & $0.795(<0.0001)^{*}$ & $0.907(<0.0001)^{*}$ \\
\hline Armwing (4) & $1(1)$ & $0.816(1)$ & $1(1)$ \\
\hline Handwing (5) & $1(1)$ & $0.333(1)$ & $1(1)$ \\
\hline Forelimb functional (6) & $1(0.0085)$ & $0.745(0.0691)$ & $1(0.0085)$ \\
\hline Hindlimb functional (7) & $0.714(0.0187)$ & $0.837(0.0061)$ & $0.837(0.0061)$ \\
\hline Abaxial skeleton (8) & $0.856(<0.0001)^{*}$ & $0.495(<0.0053)$ & $0.775(<0.0001)^{*}$ \\
\hline Primaxial skeleton (9) & $0.467(0.2596)$ & $0.286(0.5593)$ & $0.828(0.0354)$ \\
\hline
\end{tabular}

$P$ values shown in parentheses. Values in bold were statistically significant before Bonferroni correction, and asterisks indicate significance after correction $(P<0.05 / 29=0.0017)$

stages) fall within the $95 \%$ confidence intervals, indicating statistical significance (Fig. 8).

\section{Discussion}

\section{Sequence heterochrony and developmental growth}

The ossification of the clavicle is consistently the first event across birds and mammals, a pattern well-known for vertebrates [66]. Compared with birds, mammals (both bats and non-volant mammals) show a delayed ossification of the stylopod and zeugopod of both limbs, indicating that stylopod and zeugopod development in bats resembles the general pattern found in Mammalia [36]. Patterns in our results support heterochrony between the forelimb and hindlimb in bats and birds, compared to non-volant mammals (Fig. 2). Similarities between bats and birds in ossification sequences of pedal phalanges could indicate a developmental response to locomotory needs of newborns $[36,77]$. Despite behavioural differences in the neonates, and because newborn bats and birds are incapable of self-powered flight, locomotion and roosting depend mostly on hindlimb functional performance $[36,77]$. Based on recent palaeontological findings suggesting newborn pterosaurs were incapable of flight [92], we suggest that hindlimb heterochrony could be a trait shared across flying vertebrates [36, 77]. Our results support the hypothesis that accelerated development of the foot in bats correlates with the roosting ecology of newborn pups, which cannot fly and need to remain attached to either the mother or the roosting site at all times, until they achieve self-powered flight [36]. In contrast, delayed development of the carpals could be related to the functional importance of the wrist for the folding of the wing during the upstroke, a key

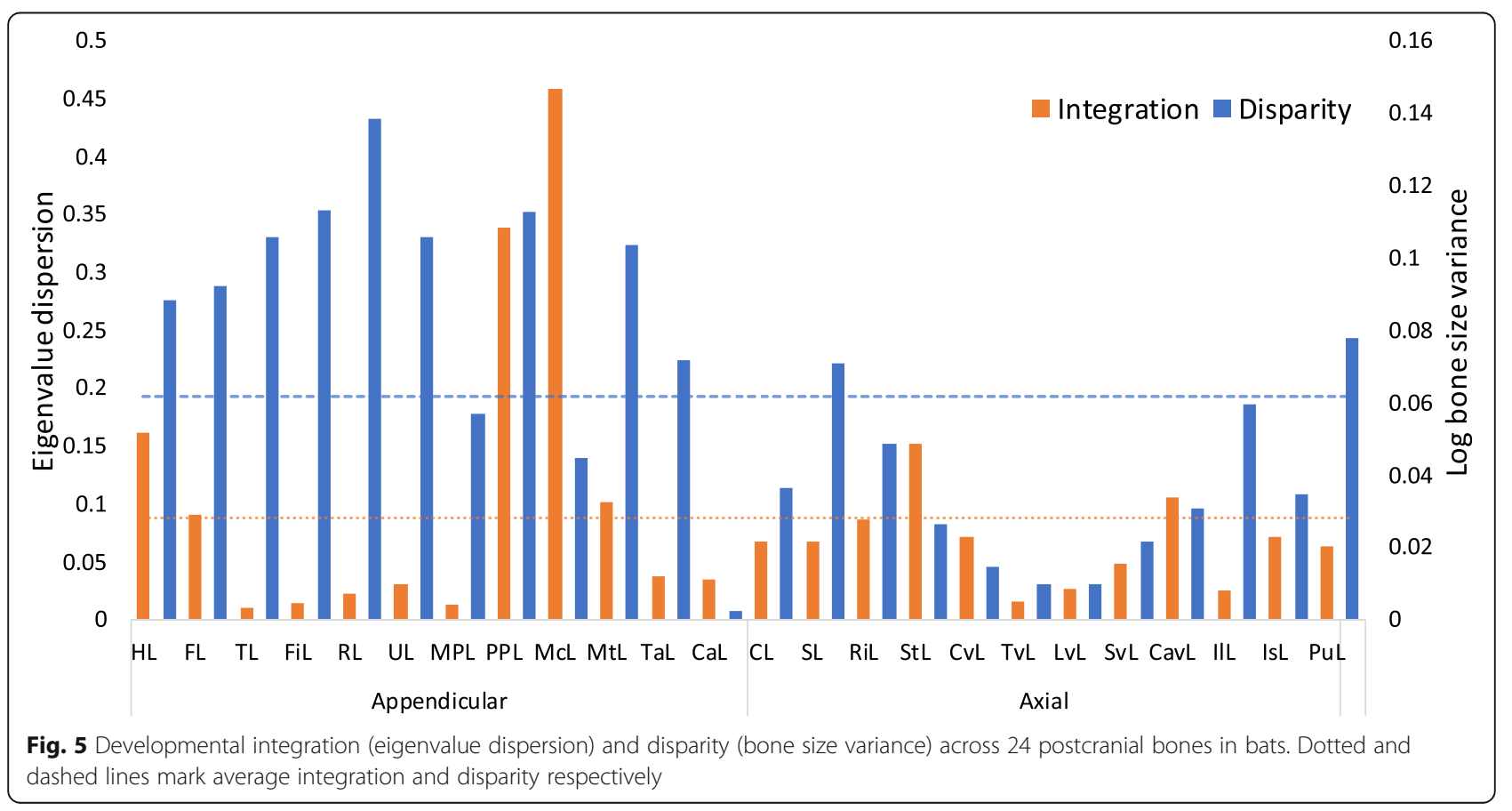




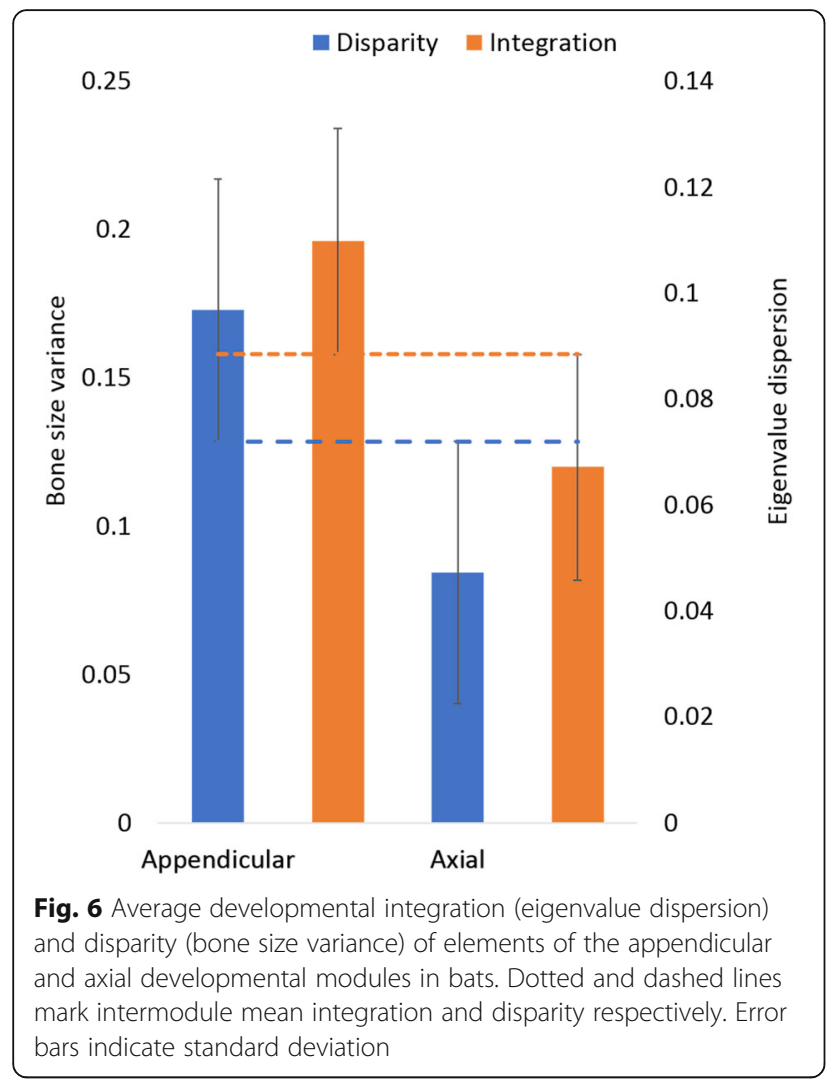

kinematic process during flight [93]. Bats also show accelerated ossification of the jaw for suckling and attachment to the mothers' nipples during flight [36].

Marked heterochrony in the ossification of the sternum of bats and birds could indicate an ontogenetic basis for flight altriciality in flying vertebrates. The presence of a sternal ridge or keel in the sternum is a crucial adaptation for flight in vertebrates, as it provides additional surface for the attachment of muscles involved in wingbeat movements [94]. Delayed ossification and longer developmental times have recently been proposed to be associated with evolvability and adaptability, although thus far only within the context of domestication $[58,98]$. Our findings of delayed sternum ossification along with its importance for locomotion across flying vertebrates [94, 95], may also be fitting with that hypothesis [58]. Finally, unsynchronised ossification of the pelvic bones reflects the different chondrogenous centres that lead to the formation of the hip as a single structure [96], a pattern previously seen in other mammalian groups but not in birds [34, 36, 77].

PCA of ossification sequences reveals a clear separation between mammals and birds along the first principal component (PC1), showing that phylogenetic relationships shaped our results (Fig. 3). Based on the apparent mammal (negative loadings) to bird (positive loadings) polarity across $\mathrm{PC} 1$, it can be argued that bones with positive loadings exemplify bird development, whereas bones with negative values exemplify mammal development. All sections of the vertebral column had negative loadings, whereas the stylopod and zeugopod of both limbs had positive loadings, indicating that axial skeleton development differentiates mammal development, whereas appendicular skeleton development differentiates bird development (Additional file 9: Table S3).

Similarities between birds and bats in postcranial development suggest an ontogenetic basis to the convergent evolution of vertebrate flight. Our results show some similarities with recent palaeontological findings that informed the prenatal development of pterosaurs [92]. It is hypothetised that newborn pterosaurs were incapable of self-powered flight due to an altricial wing, a trait shared with bats and birds [36, 77, 92]. Moreover, based on our

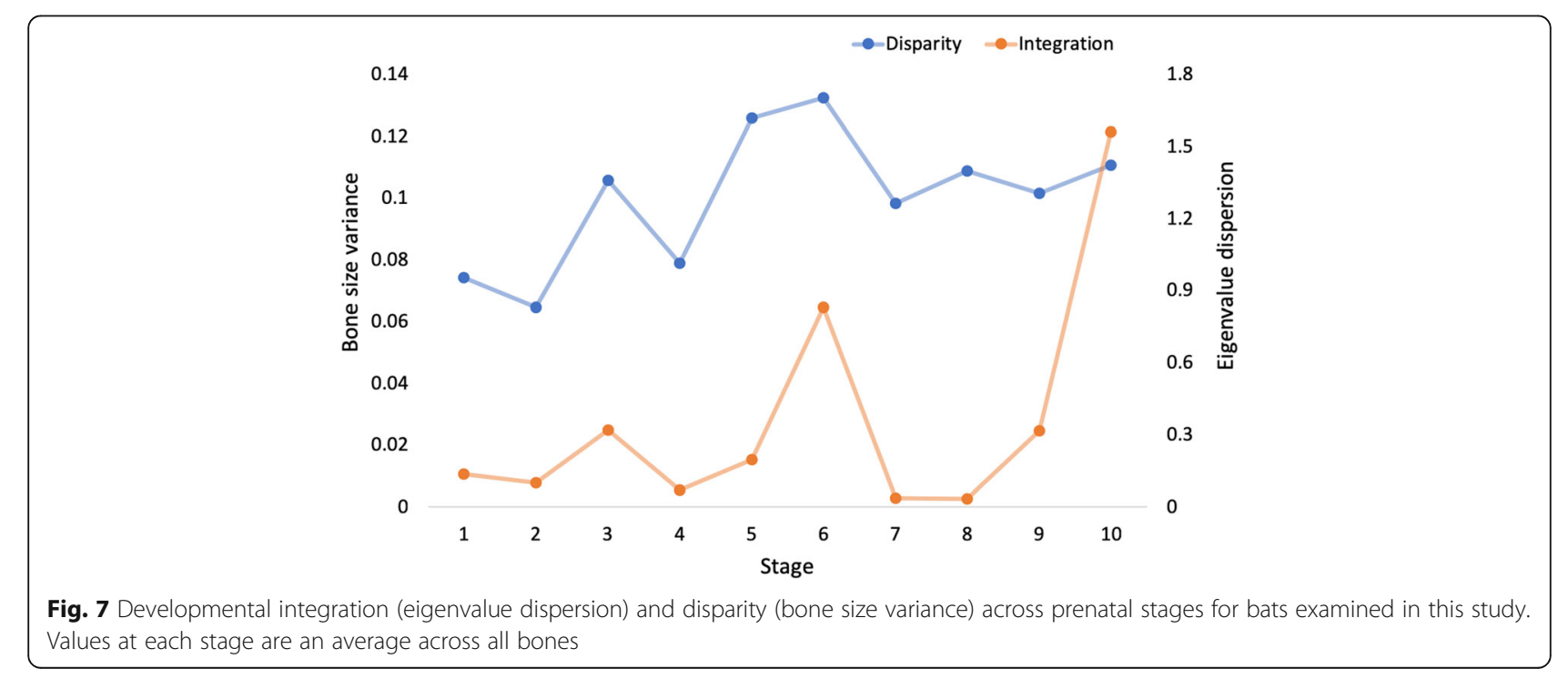




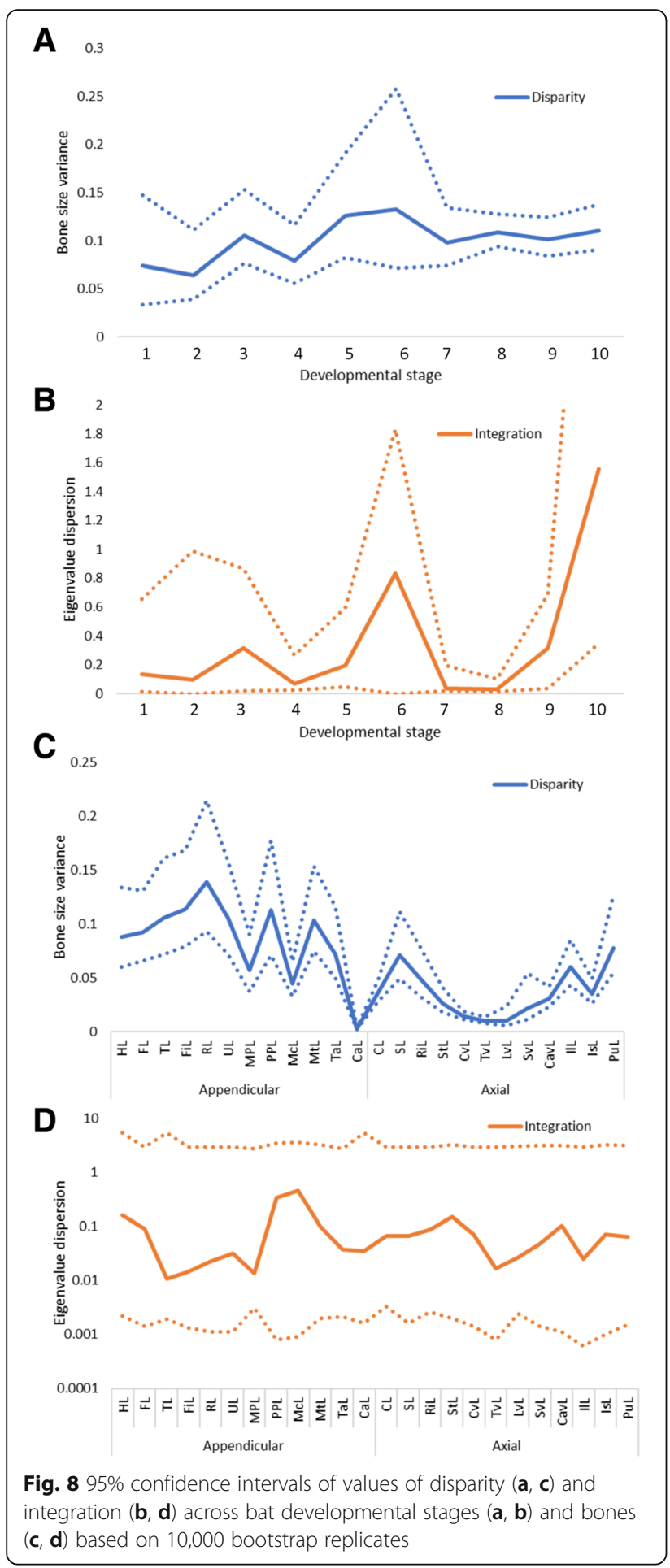

results, we can suggest a shared ontogenetic basis to flight altriciality, as a general delay in the ossification of the wing and sternum compared with the hindlimb is found across all flying vertebrate groups [36, 77, 92]. Relative timing of morphogenesis and incomplete prenatal development could act as an evolutionary promoter of adaptability and evolvability in the forelimb of flying vertebrates, facilitating flight adaptations to evolve [58]. Previously, prenatal developmental timing has been associated with evolvability in cranial shape of carnivorans, also showing an ontogenetic source for variability associated with domestication in canids [58, 97, 98].

Our results also showed that the development of the vertebral column of bats deviates from both the non-volant mammals and birds. In comparison to other mammals, unique morphological features found in the vertebral column of bats have been linked to the roosting and feeding ecology of the species [99]. Our findings of sequence heterochrony in the vertebral column indicate that the morphological patterns found in this region in previous studies could have an ontogenetic basis, originating during the prenatal development of the skeleton [47, 99].

Evolutionary changes in bone size have been correlated with heterochronic development of those structures [100]. Our result that bones that grow to be relatively small in the adult have a late ossification onset does not reflect this phenomenon (Fig. 5). Instead, our results could reflect that at the stage sampled much of the growth for the elements examined here was yet to be completed (i.e. postnatally), leading to a narrower depiction of its total growth path [101]. Future studies could combine pre- and postnatal developmental data to trace the complete development of the hip.

\section{Developmental modularity}

Our analysis did not reject the hypothesis that postcranial developmental modularity is present in bats, birds and non-volant mammals (Figs. 3, 4, Table 3). The presence of an axial-appendicular partition in both mammal groups, not found in birds, could indicate that flight did not repattern ontogenetic modularity in flying vertebrates, as bats and non-volant mammals shared the same pattern for postcranial modularity. Furthermore, our results supported the presence of an appendicular skeleton module, previously unknown in bats [102], and an axial module previously found in placental prenatal development [102]. We suggest a developmental module hypothesis, where the shared LPM-derived origin of all bones of the appendicular skeleton develop as a unit [103].

Modularity in the appendicular skeleton of mammals has been reported to respond to functional pressures and selection on short times scales, as in domestication $[104,105]$. Presence of developmental modularity in mammals has revealed a clear ontogenetic division between marsupials and placentals, each group presenting different patterns of postcranial modularity [102]. In particular, placental mammals showed strong evidence of an appendicular module and a module including both girdles [102]. However, previous studies suggested that bats are an exception to this trend, showing low 
covariation between hind- and forelimb both during their development and adulthood [23, 102, 106, 107], in contrast to our results. Each of these studies focused on modularity in mammals as a whole, including only one bat species in their sample. The contrasting results could be due to differences in sample composition, with low bat species representation obscuring patterns only discernible when analysing multiple species representing different lineages. With 14 bat species, our study represents the most comprehensive quantitative study of prenatal developmental biology in chiropterans to date. Also, our results of developmental modularity were informed by two different datasets that combined sequence heterochrony and metric growth data, contrary to previous studies that focused only on one.

Our two sets of results could indicate that the functional differences between the forelimb and hindlimb in adult bats are not reflected during prenatal development $[15,108]$. Moreover, integrated development of homologous structures could facilitate morphological diversity, enabling novel functional ecologies to evolve [46, 59, 62, 109]. The latter may indicate that the correlated development of both limbs in bats could facilitate morphological disparity in adult forms. In bats, neonate hindlimb size is similar to its adult size whereas neonate forelimb size is about one third of adult size [36]. Since the forelimb is not developed sufficiently for flight at birth and requires extended postnatal time to be large enough to be fully functional, it was suggested that prenatal bats invest in earlier development of the hindlimb [36]. Given the present results, we hypothesise that modular development in the appendicular skeleton could represent a trade-off between the accelerated development of the foot (and functionality in newborns), and the delayed development of the wing (and its functionality in later development; [93]). Delayed prenatal development has been linked to higher adaptability and evolvability to environmental pressures in domesticated carnivorans [58].

\section{Disparity and integration}

High levels of disparity in the zeugopod of both limbs document the developmental basis of its functional variability (Fig. 4). Compared to the ancestral mammalian condition, zeugopod reduction is a convergent trait common across multiple clades [110]. This reduction arguably enabled locomotory specialisations that led to the adaptive radiation of mammals [110]. Diminished growth rate of the zeugopod - in particular the ulna and fibula - is a developmental process that has been found in several different mammal groups, arguing for a shared ontogenetic mechanism for zeugopod reduction [110]. Our results indicate that zeugopod development is highly variable across bat species, possibly reflecting functional differences associated with ecological traits of the species (e.g. flying behaviours, locomotory specialisations, and body sizes) [32, 111, 112]. Forearm length is widely used to inform field identification of bat species, providing a good indicator of the interspecific morphological delimitation in many taxa [113]. Additionally, relative forearm length is also a good estimate of several biomechanical properties of the wing that reflect ecological differences across species [114]. We hypothesise that high prenatal disparity of the zeugopod could be indicative of ecomorphological diversity in adult bats.

Our PCA of species could reflect functional differences by showing that $C$. sphinx (the only plant-eater and non-echolocating species in our sample for this analysis) was the most dissimilar (Additional file 10: Figure S7 and Additional file 11: Table S4). Plant-visiting bats exhibit foraging behaviours uncommon in animalivorous species (e.g. prolonged hovering flight) that could represent novel functional needs for the postcranium. However, the PCA also shows that the subordinal spaces did not overlap, raising the question of whether our results evidence a phylogenetic signal, rather than functional. Descriptions of the broad foraging guilds for these bat families suggest that all animalivorous species in our sample are aerial hawkers [115], indicating a phylogenetic signal in our results. Nevertheless, the ecology of some of the species is either poorly known (e.g. Aselliscus) or highly adaptable (e.g. Kerivoula and Myotis species are known to switch between hawking and gleaning) $[116,117]$. Expanding the sample to include frugivorous yangochiropteran species (i.e. phyllostomids) could yield further insights.

Phylogenetic studies have reconstructed clade-specific evolutionary trajectories of joint and muscle reduction in the wings of bats, closely associated with flying behaviours in response to feeding strategies [118]. Such correspondence between ecological diversity and developmental differences has been previously reported in other mammals [47]. Finally, low levels of integration in the zeugopod and a generalised increase in disparity indicate that integration could promote disparity during prenatal development [59].

Differences in disparity between modules also illustrate the ontogenetic basis of the phenotypic diversity and functional variability of the limbs in bats. Prenatal development has been suggested to respond to the functional needs of the neonates, rather than the ecological niche of the species [36]. As such, lower than average disparity in the axial module suggests that this section of the skeleton does not experience high evolutionary pressure to diversify prenatally $[15,36,119,120]$.

Our results provide strong evidence for increase in disparity over ontogeny (Fig. 7), a pattern rarely reported in mammals [59]. Moreover, ours represents the 
first report of this pattern both in bats and in prenatal development. Previous studies have shown that integration canalises phenotypic variation in deep-time [59, 121-124], and that changes in size can work as evolutionary buffers for adaptive radiation [125]. Differences between morphological canalisation over deep time and our results across developmental time support the hypothesis that integration facilitates disparity from an ontogenetic perspective $[59,121]$. This congruence in temporal patterns differs from the mismatch in patterns of integration and disparity found across bones and modules, demonstrating that temporality rather than functionality shapes the interaction between developmental disparity and integration $[49,59]$.

\section{Conclusions}

Combining data of sequence heterochrony and developmental growth from 14 bat species, this study represents the most comprehensive quantitative analysis of chiropteran prenatal ossification to date. Sequence heterochrony between the autopod of fore- and hindlimbs could reflect functional needs of the newborn, rather than ecological aspects of the adult. Sequence heterochrony also showed that bats have similarities with birds in the ossification of structures involved in flight (i.e. handwing and sternum), suggesting that flight altriciality and early ossification of pedal phalanges and sternum are common across flying vertebrates. Developmental modularity was detected both in ossification sequence and metric growth of the postcranium, suggesting an axial-appendicular partition of the postcranium that deviates from the general pattern reported for mammals. This partition possibly corresponds to genetic and ontogenetic aspects of the development of the postcranium (e.g. the LPM-derived nature of all appendicular bones), rather than ecomorphological characteristics of bats. The marked difference in values of disparity between modules reflects the phenotypic diversity of the appendicular skeleton in response to interspecific functional differences of the wing. Our results reject the hypothesis that morphological variation in the fore- and hindlimbs of bats is dissociated. Integration and disparity increased across prenatal stages, supporting the hypothesis that integration facilitates disparity. Moreover, we found that this interaction is only evident from a temporal perspective (i.e. across developmental time) rather than from a morphofunctional one (i.e. between functional modules of the skeleton). Finally, our results show not only an increase in disparity across developmental time, but also a delayed ossification in highly adaptable and evolvable regions, both patterns rarely reported in wild mammals.

\section{Additional files}

Additional file 1: Figure S1. Flowchart summarising the methodology used in our study. (TIFF $363 \mathrm{~kb}$ )

Additional file 2: Figure S2. LDA of staging system implemented for bats in this study. (TIFF $266 \mathrm{~kb}$ )

Additional file 3: Table S1. Average values $(\mathrm{mm})$ of 25 postcranial linear measurements of 66 specimens of 11 bat species and all species pooled. Standard deviation in parenthesis. (CSV $3 \mathrm{~kb}$ )

Additional file 4: Figure S3. PCA of linear measurements of 24 postcranial bones in bat foetuses. Bones are grouped reflecting the axial and appendicular modules found in our Kendall's T modularity analysis. (TIFF 533 kb)

Additional file 5: Figure S4. Generalized Linear Model (GLM) of integration (Eigenvalue dispersion) and disparity (bone size variance) values across all 24 bones measured and all bat species pooled. Each point represents a single skeletal element. (PNG $18 \mathrm{~kb}$ )

Additional file 6: Table S2 Description of developmental stages 1-10 based on $C R L$ ranges and ossification events that characterise each stage. " $X$ " represents the ossification onset of a given bone. (CSV $1 \mathrm{~kb}$ )

Additional file 7: Figure S5. Scatterplot of integration (Eigenvalue dispersion) and disparity (bone size variance) values in bats against number of specimens in each stage. (PNG $19 \mathrm{~kb}$ )

Additional file 8: Figure S6. GLM of integration (Eigenvalue dispersion) and disparity (bone size variance) values across developmental time in bats examined. Each point represents a developmental stage. (PNG 15 kb)

Additional file 9: Table S3. PCA loadings of relative ossification rank for 24 postcranial bones. (CSV $1 \mathrm{~kb}$ )

Additional file 10: Figure S7. PCA of bat species based on metric growth data. Ellipses show the developmental space of both suborders. (PNG 594 kb)

Additional file 11: Table S4. Bone size variance (disparity) and eigenvalue dispersion (integration) values of 24 postcranial bones of nine bat species included in this study. Left and right boxes include bones of the appendicular and axial module respectively. Int = Integration,

Disp = disparity. (CSV 2 kb)

Additional file 12: Ossification sequence data used in this study. (XLS $40 \mathrm{~kb}$ ) Additional file 13: Metric growth data used in this study. (XLSX 17 kb)

\section{Abbreviations}

CaL: Carpal Length; CavL: Caudal Vertebral Width; CL: Clavicular Length; CRL: Crown to Rump Length; CVL: Cervical Vertebral Width; FiL: Fibular Length; FL: Femoral Length; GLM: Generalised Linear Model; HL: Humeral Length; IIL: Ilium Length; IsL: Ischium Length; LDA: Linear Discriminant Function Analysis; LPM: Lateral Plate Mesoderm; LVL: Lumbar Vertebral Width; McL: Metacarpal Length; MPL: Manual Phalanges Length; MtL: Metatarsal Length; PCA: Principal Component Analysis; PPL: Pedal Phalanges Length; PuL: Pubis bone Length; RL: Radial Length; RL: Rib Length; SL: Scapular Length; StL: Sternum Length; SvL: Sacral Vertebral Width; TaL: Tarsal Length; TL: Tibial Length; TVL: Thoracic Vertebral Width; UL: Ulnar Length

\section{Acknowledgments}

We thank the directorates of the Vietnam National Parks and Nature Reserves where we conducted our surveys and Vietnam Administration of Forestry of the Vietnamese Ministry of Agriculture and Rural Development and People's Committees of Provinces for generously assisting the study.

\section{Funding}

CLA is supported by the Australian Government Research Training Program Scholarship and the PANGEA Research Centre at UNSW provided additional support. LABW and SJH are supported by the Discovery Program of the Australian Research Council (DE150100862, DP130100197, DP170101420 and DP180100792). DK is supported by KAKENHI (18H04816, 18H02492, 18 K19359, and 26711023) and NTS by NAFOSTED (106-NN.05-2016.14). Funders had no role in the design of the study and collection, analysis, and interpretation of data and in writing the manuscript. 


\section{Availability of data and materials}

All data generated or analysed during this study are included in the supplementary information to this article (Additional files 12 and 13).

\section{Authors' contributions}

CLA, SJH and LABW designed the study. CLA gathered and analysed the data. CLA, SJH, LABW and DK wrote the manuscript. DK and NTS sampled the specimens, and DK prepared and scanned the specimens. All authors read and approved the final manuscript.

\section{Ethics approval and consent to participate}

All research protocols used in the current experiments were approved by the Institute of Ecology and Biological Resources, Vietnam Academy of Sciences and Technology. Animals were euthanized by cervical dislocation, and the methods were conducted in accordance with the approved animal ethics guidelines.

\section{Consent for publication}

Not applicable.

\section{Competing interests}

The authors declare that they have no competing interests.

\section{Publisher's Note}

Springer Nature remains neutral with regard to jurisdictional claims in published maps and institutional affiliations.

\section{Author details}

'PANGEA Research Centre, School of Biological, Earth \& Environmental Sciences, University of New South Wales, Sydney, NSW 2052, Australia. ${ }^{2}$ University Museum, University of Tokyo, Tokyo, Japan. ${ }^{3}$ Department of Humanities and Sciences, Musashino Art University, Tokyo, Japan. ${ }^{4}$ Department of Vertebrate Zoology, Institute of Ecology and Biological Resources, Vietnam Academy of Sciences and Technology, Hanoi, Vietnam. ${ }^{5}$ Vietnam Academy of Science and Technology, Graduate University of Science and Technology, Hanoi, Vietnam.

Received: 31 July 2018 Accepted: 21 February 2019 Published online: 12 March 2019

\section{References}

1. Rayner JM. The evolution of vertebrate flight. Biol J Linn Soc. 1988;34(3): 269-87.

2. Tokita M. How the pterosaur got its wings. Biol Rev Camb Philos Soc. 2015; 90(4):1163-78.

3. Organ $\mathrm{CL}$, Shedlock AM. Palaeogenomics of pterosaurs and the evolution of small genome size in flying vertebrates. Biol Lett. 2009;5(1):47-50.

4. Fong JJ, Brown JM, Fujita MK, Boussau B. A Phylogenomic Approach to Vertebrate Phylogeny Supports a Turtle-Archosaur Affinity and a Possible Paraphyletic Lissamphibia. PLoS One. 2012;7(11):e48990.

5. Amador LI, Arevalo RLM, Almeida FC, Catalano SA, Giannini NP. Bat systematics in the light of unconstrained analyses of a comprehensive molecular Supermatrix. J Mamm Evol. 2018;25(1):37-70.

6. Stroud JT, Losos JB. Ecological opportunity and adaptive radiation. Annu Rev Ecol Evol Syst. 2016;47(1):507-32

7. Butler RJ, Benson RBJ, Barrett PM. Pterosaur diversity: untangling the influence of sampling biases, Lagerstätten, and genuine biodiversity signals. Palaeogeogr Palaeoclimatol Palaeoecol. 2013;372:78-87.

8. Dumont ER. Bone density and the lightweight skeletons of birds. Proc R Soc B Biol Sci. 2010;277(1691):2193-8.

9. Cubo J, Casinos A. The variation of the cross-sectional shape in the long bones of birds and mammals. Annales des Sciences Naturelles - Zoologie et Biologie Animale. 1998;19(1):51-62.

10. Currey JD, Alexander MR. The thickness of the walls of tubular bones. J Zool. 1985;206(4):453-68.

11. Lee $A H$, Simons E. Wing bone laminarity is not an adaptation for torsional resistance in bats. PeerJ. 2015;3:e823.

12. Kapusta A, Suh A, Freschotte C. Dynamics of genome size evolution in birds and mammals. Proc Natl Acad Sci. 2017;114(8):E1460-9.

13. Eiting TP, Gunnell GF. Global completeness of the bat fossil record. J Mamm Evol. 2009;16(3):151-73.
14. Arita HT, Fenton MB. Flight and echlocation in the ecology and evolution of bats. Trends Ecol Evol. 1997;12(2):53-8.

15. Adams RA. Morphogenesis in Bat Wings: Linking Development, Evolution and Ecology. Cells Tissues Organs. 2007;187(1):13-23.

16. Simmons NB, Seymour KL, Habersetzer J, Gunnell GF. Primitive early Eocene bat from Wyoming and the evolution of flight and echolocation. Nature. 2008;451(7180):818-21.

17. Veselka N, McErlain DD, Holdsworth DW, Eger JL, Chhem RK, Mason MJ, Brain KL, Faure PA, Fenton MB. A bony connection signals laryngeal echolocation in bats. Nature. 2010:463(7283):939-42.

18. Cooper L, Cretekos CJ, Sears KE. The evolution and development of mammalian flight. Wiley Interdiscip Rev Dev Biol. 2012;1(5):773-9.

19. Adams RA, Shaw JB. Time's arrow in the evolutionary development of bat flight. In: Adams R, Pedersen S, editors. Bat evolution, ecology and conservation. New York: Springer; 2013. p. 21-46.

20. Jones G, Teeling EC. The evolution of echolocation in bats. Trends Ecol Evol. 2006:21(3):149-56.

21. Teeling EC, Scally M, Kao D, Romagnoli M, Springer MS, Stanhope M. Molecular evidence regarding the origin of echolocation and flight in bats. Nature. 2000;403:188-92.

22. Wang Z, Zhu T, Xue H, Fang N, Zhang J, Zhang L, Pang J, Teeling EC, Zhang S. Prenatal development supports a single origin of laryngeal echolocation in bats. Nat Ecol Evol. 2017:1:21.

23. Weisbecker V, Goswami A, Wroe S, Sanchez-Villagra MR. Ossification heterochrony in the therian postcranial skeleton and the marsupialplacental dichotomy. Evolution. 2008;62(8):2027-41.

24. Koyabu D, Endo H, Mitgutsch C, Suwa G, Catania KC, Zollikofer CPE, Oda S-I, Koyasu K, Ando M, Sánchez-Villagra MR. Heterochrony and developmental modularity of cranial osteogenesis in lipotyphlan mammals. EvoDevo. 2011;2:21.

25. Maxwell EE, Harrison LB. Methods for the analysis of developmental sequence data. Evol Dev. 2009;11(1):109-19.

26. Hendrikse JL, Parsons TE, Hallgrimsson B. Evolvability as the proper focus of evolutionary developmental biology. Evol Dev. 2007;9(4):393-401.

27. Hall BK. Evo-devo or devo-evo--does it matter. Evol Dev. 2000;2(4):177-8.

28. Organ $\mathrm{CL}$, Cooper LN, Hieronymus TL. Macroevolutionary developmental biology: embryos, fossils, and phylogenies. Dev Dyn. 2015:244(10):1184-92

29. Nojiri T, Werneburg I, Son NT, Tu VT, Sasaki T, Maekawa Y, Koyabu D. Prenatal cranial bone development of Thomas's horseshoe bat (Rhinolophus thomasi): with special reference to petrosal morphology. J Morphol. 2018; 279(6):809-27.

30. McNamara KJ. Heterochrony: the evolution of development. Evolution. 2012 5(2):203-18

31. Raff RA. The shape of life: genes, development, and the evolution of animal form. Chicago: University of Chicago Press; 1996

32. Bininda-Emonds OR, Jeffery JE, Sanchez-Villagra MR, Hanken J, Colbert M, Pieau C, Selwood L, Ten Cate C, Raynaud A, Osabutey CK, et al. Forelimbhindlimb developmental timing changes across tetrapod phylogeny. BMC Evol Biol. 2007;7:182

33. Cretekos CJ, Wang Y, Green ED, Martin JF, Rasweiler JJ, Behringer RR. Regulatory divergence modifies limb length between mammals. Genes Dev. 2008:22(2):141-51.

34. Wilson LAB, Schradin C, Mitgutsch C, Galliari FC, Mess A, Sánchez-Villagra MR. Skeletogenesis and sequence heterochrony in rodent evolution, with particular emphasis on the African striped mouse, Rhabdomys pumilio (Mammalia). Org Divers Evol. 2010;10(3):243-58.

35. Ross D, Marcot JD, Betteridge KJ, Nascone-Yoder N, Bailey CS, Sears KE. Constraints on mammalian forelimb development: insights from developmental disparity. Evolution. 2013;67(12):3645-52.

36. Koyabu D, Son N. Patterns of postcranial ossification and sequence heterochrony in bats: life histories and developmental trade-offs. J Exp Zool B Mol Dev Evol. 2014;322(8):607-18.

37. Smith KK. Sequence heterochrony and the evolution of development. Morphol. 2002;252(1):82-97.

38. Werneburg I, Tzika AC, Hautier L, Asher RJ, Milinkovitch MC, Sánchez-Villagra MR. Development and embryonic staging in non-model organisms: the case of an afrotherian mammal. J Anat. 2013:222(1) $2-18$.

39. Hautier L, Stansfield F, Allen T, Asher R. Skeletal development in the African elephant and ossification timing in placental mammals. Proc Royal Soc Lond B Biological Sci. 2012;279:2188-95.

40. Smith KK. Heterochrony revisited: the evolution of developmental sequences. Biol J Linn Soc. 2001;73:169-86. 
41. Smith KK. Time's arrow: heterochrony and the evolution of development. Int J Dev Biol. 2003;47(7-8):613-21.

42. Hafner M, Remsen J Jr, Lanyon S. Bird versus mammal morphological diversity. Evolution. 1984;38(5):1154-6.

43. Jones KE, Safi K. Ecology and evolution of mammalian biodiversity introduction. Philos T R Soc B. 2011;366(1577):2451-61.

44. Hautier L, Bennett NC, Viljoen H, Howard L, Milinkovitch MC, Tzika AC, Goswami A, Asher RJ. Patterns of ossification in southern versus northern placental mammals. Evolution. 2013;67(7):1994-2010.

45. Koyabu D. Prenatal postcranial development in two species of sympatric Japanese wood mice (Apodemus argenteus and A. speciosus): a comparison of arboreal versus terrestrial congeners. J Vet Med Sci. 2017;79(5):952-6.

46. Klingenberg CP. There's something afoot in the evolution of ontogenies. BMC Evol Biol. 2010;10:221.

47. Wilson LAB, Sanchez-Villagra MR. Diversity trends and their ontogenetic basis: an exploration of allometric disparity in rodents. P Roy Soc B-Biol Sci. 2010;277(1685):1227-34

48. Wilson LAB. Allometric disparity in rodent evolution. Ecol Evol. 2013;3(4): 971-84

49. Randau M, Goswami A. Unravelling intravertebral integration, modularity and disparity in Felidae (Mammalia). Evol Dev. 2017;19(2):85-95.

50. Randau M, Goswami A. Shape covariation (or the lack thereof) between vertebrae and other skeletal traits in felids: the whole is not always greater than the sum of parts. Evol Biol. 2018;45(2):196-210.

51. Adams DC, Nistri A. Ontogenetic convergence and evolution of foot morphology in European cave salamanders (family: Plethodontidae). BMC Evol Biol. 2010;10:216.

52. Esquerré D, Sherratt $E$, Keogh JS. Evolution of extreme ontogenetic allometric diversity and heterochrony in pythons, a clade of giant and dwarf snakes. Evolution. 2017;71(12):2829-44.

53. Gerber S, Eble GJ, Neige P. Allometric space and allometric disparity: a developmental perspective in the macroevolutionary analysis of morphological disparity. Evolution. 2008;62(6):1450-7.

54. Ramirez-Chaves HE, Wroe SW, Selwood L, Hinds LA, Leigh C, Koyabu D, Kardjilov N, Weisbecker V. Mammalian development does not recapitulate suspected key transformations in the evolutionary detachment of the mammalian middle ear. Proc Biol Sci. 2016;283:20152606.

55. Wilson LAB. Comparison of prenatal and postnatal ontogeny: cranial allometry in the African striped mouse (Rhabdomys pumilio). J Mammal. 2011;92(2):407-20.

56. Zelditch ML, Calamari ZT, Swiderski DL. Disparate Postnatal Ontogenies Do Not Add to the Shape Disparity of Infants. Evol Biol. 2016;43(2):188-207.

57. Halley AC. Prenatal brain-body allometry in mammals. Brain Behav Evol. 2016:88:14-24.

58. Werneburg I, Geiger M. Ontogeny of domestic dogs and the developmental foundations of carnivoran domestication. J Mamm Evol. 2017:24(3):323-43.

59. Goswami A, Smaers JB, Soligo C, Polly PD. The macroevolutionary consequences of phenotypic integration: from development to deep time. Philos Trans R Soc Lond Ser B Biol Sci. 2014;369(1649):20130254.

60. Swartz SM, Konow N. Advances in the study of bat flight: the wing and the wind 1. Can J Zool. 2015;93:977-90.

61. Gerber S. On the Relationship between the Macroevolutionary Trajectories of Morphological Integration and Morphological Disparity. PLoS One. 2013; 8(5):e63913.

62. Klingenberg CP. Studying morphological integration and modularity at multiple levels: concepts and analysis. Philos Trans R Soc Lond Ser B Biol Sci. 2014;369(1649):20130249

63. Klingenberg C. Morphological integration and developmental modularity. Ecol Evol Syst. 2008;39:115-32.

64. Wagner GP, Altenberg L. Perspective: complex adaptations and the evolution of evolvability. Evolution. 1996;50(3):967-76.

65. Wagner GP, Pavlicev M, Cheverud JM. The road to modularity. Nat Rev Genet. 2007;8(12):921-31.

66. Sánchez-Villagra MR. Comparative patterns of postcranial ontogeny in therian mammals: an analysis of relative timing of ossification events. J Exp Zool. 2002;294(3):264-73.

67. Thean T, Kardjilov N, Asher RJ. Inner ear development in cetaceans. J Anat. 2017;230(2):249-61.

68. Santana SE, Grosse IR, Dumont ER. Dietary hardness, loading behavior, and the evolution of skull form in bats. Evolution. 2012;66(8):2587-98.
69. Dickinson M. Animal locomotion: a new spin on bat flight. Curr Biol. 2008; 18(11):468-70.

70. Riskin DK, Bertram JEA, Hermanson JW. Testing the hindlimb-strength hypothesis: non-aerial locomotion by Chiroptera is not constrained by the dimensions of the femur or tibia. J Exp Biol. 2005;208(7):1309-19.

71. Riskin DK, Parsons S, Schutt WA Jr, Carter GG, Hermanson JW. Terrestrial locomotion of the New Zealand short-tailed bat Mystacina tuberculata and the common vampire bat Desmodus rotundus. J Exp Biol. 2006;2009(9):1725-36.

72. Riskin DK, Willis DJ, Iriarte-Diaz J, Hedrick TL, Kostandov M, Chen J, Laidlaw DH, Breuer KS, Swartz SM. Quantifying the complexity of bat wing kinematics. J Theor Biol. 2008;254(3):604-15.

73. Adams RA: Wing ontogeny, shifting niche dimensions, and adaptive landscapes In: Ontogeny, Functional Ecology and Evolution of Bats. Edited by Adams RA, Pedersen SC. Cambridge: Cambridge University Press; 2000: 275-316.

74. Koyabu D, Werneburg I, Morimoto N, Zollikofer CPE, Forasiepi A, Endo H, Kimura J, Ohdachi SD, Son NT, Sánchez-Villagra MR. Mammalian skull heterochrony reveals modular evolution and a link between cranial development and brain size. Nat Commun. 2014;5:3625.

75. Spoor CF, Zonneveld FW, Macho GA. Linear measurements of cortical bone and dental enamel by computed-tomography - applications and problems. Am J Phys Anthropol. 1993;91(4):469-84.

76. Adams RA. Comparative Skeletogenesis of the forearm of the little Brown bat (Myotis lucifugus) and the Norway rat (Rattus norvegicus). J Morphol. 1992;214(3):251-60.

77. Maxwell EE, Harrison LB, Larsson HCE. Assessing the phylogenetic utility of sequence heterochrony: evolution of avian ossification sequences as a case study. Zoology. 2010;113(1):57-66.

78. Goswami A. Cranial modularity and sequence heterochrony in mammals. Evol Dev. 2007;9(3):290-8.

79. Sánchez-Villagra MR, Goswami A, Weisbecker V, Mock O, Kuratani S. Conserved relative timing of cranial ossification patterns in early mammalian evolution. Evol Dev. 2008;10(5):519-30.

80. Hammer O, Harper DAT, Ryan PD. PAST: paleontological statistics software package for education and data analysis. Palaeontol Electron. 2001;4:1.

81. Zeileis A, Grothendieck G, Ryan JA, Ulrich JM, Andrews F: zoo: S3 Infrastructure for Regular and Irregular Time Series R (S-Plus) Functions. 1.81 ed. 2018.

82. Burke AC, Nowicki JL. A new view of patterning domains in the vertebrate mesoderm. Dev Cell. 2003;4(2):159-65.

83. Buchholtz EA, Stepien CC. Anatomical transformation in mammals: developmental origin of aberrant cervical anatomy in tree sloths. Evol Dev. 2009;11(1):69-79.

84. Hautier L, Weisbecker V, Sanchez-Villagra MR, Goswami A, Asher RJ. Skeletal development in sloths and the evolution of mammalian vertebral patterning. P Natl Acad Sci USA. 2010;107(44):18903-8.

85. Pavlicev M, Cheverud JM, Wagner GP. Measuring morphological integration using eigenvalue variance. Evol Biol. 2009;36(1):157-70.

86. Cretekos CJ, Weatherbee SD, Chen CH, Badwaik NK, Niswander L, Behringer RR, Rasweiler JJ. Embryonic staging system for the short-tailed fruit bat, Carollia perspicillata, a model organism for the mammalian order Chiroptera, based upon timed pregnancies in captive-bred animals. Dev Dyn. 2005; 233(3):721-38.

87. Wyant KA, Adams RA. Prenatal growth and development in the Angolan free-tailed bat, Mops condylurus (Chiroptera : Molossidae). J Mammal. 2007; 88(5):1248-51.

88. Wang Z, Han N, Racey PA, Ru BH, He GM. A comparative study of prenatal development in Miniopterus schreibersii fuliginosus, Hipposideros armiger and H. pratti. BMC Dev Biol. 2010;10:10.

89. Tokita M, Abe T, Suzuki K. The developmental basis of bat wing muscle. Nat Commun. 2012;3:1302

90. Hockman D, Mason MK, Jacobs DS, Illing N. The role of early development in mammalian limb diversification: a descriptive comparison of early limb development between the Natal longfingered bat (Miniopterus natalensis) and the mouse (Mus musculus). Dev Dyn. 2009;238(4):965-79.

91. Canty A, Ripley BS. boot: Bootstrap R (S-Plus) Functions. 1.3-20 ed; 2017.

92. Wang XL, Kellner AWA, Jiang SX, Cheng X, Wang Q, Ma YX, Paidoula Y, Rodrigues $\mathrm{T}$, Chen $\mathrm{H}$, Sayao JM, et al. Egg accumulation with 3D embryos provides insight into the life history of a pterosaur. Science. 2017;358(6367):1197-201.

93. Riskin DK, Bergou A, Breuer KS, Swartz SM. Upstroke wing flexion and the inertial cost of bat flight. Proc Biol Sci. 2012;279(1740):2945-50. 
94. Norberg UM. Vertebrate flight, mechanics, physiology, morphology, ecology and evolution. 1st ed. Berlin: Springer-Verlag; 1990.

95. Norberg RA, Rayner JMV. Ecological morphology and flight in bats (Mammalia; Chiroptera): wing adaptations, flight performance, foraging strategy and echolocation. Philos Trans R Soc Lond Ser B Biol Sci. 1987;316: 335-427.

96. Ruth EB. A study of the development of the mammalian pelvis. Anat Rec. 1932:53(2):207-25.

97. Wilson $L A B$. The evolution of ontogenetic allometric trajectories in mammalian domestication. Evolution. 2018;72(4):867-77.

98. Machado FA, Zahn TMG, Marroig G. Evolution of morphological integration in the skull of Carnivora (Mammalia): changes in Canidae lead to increased evolutionary potential of facial traits. Evolution. 2018;72(7):1399-419.

99. Gaudioso PJ, Diaz MM, Barquez RM. Morphology of the axial skeleton of seven bat genera (Chiroptera: Phyllostomidae). An Acad Bras Cienc. 2017; 89(3):2341-58

100. Keyte AL, Smith KK. Heterochrony and developmental timing mechanisms: Changing ontogenies in evolution. Semin Dev Cel Biol. 2014;34:99-107.

101. Werneburg I, Laurin M, Koyabu D, Sanchez-Villagra MR. Evolution of organogenesis and the origin of altriciality in mammals. Evol Dev. 2016; 18(4):229-44.

102. Goswami A, Weisbecker V, Sanchez-Villagra MR. Developmental modularity and the marsupial-placental dichotomy. J Exp Zool B Mol Dev Evol. 2009; 312B(3):186-95.

103. Wallin J, Wilting J, Koseki $H$, Fritsch $R$, Christ B, Balling R. The role of Pax-1 in axial skeleton development. Development. 1994;120(5):1109-21.

104. Hanot P, Herrel A, Guintard C, Cornette R. The impact of artificial selection on morphological integration in the appendicular skeleton of domestic horses. J Anat. 2018;232(4):657-73.

105. Hanot P, Herrel A, Guintard C, Cornette R. Morphological integration in the appendicular skeleton of two domestic taxa: the horse and donkey. Proc Biol Sci. 2017;284:20171241.

106. Young NM, Hallgrímsson B. Serial homology and the evolution of mammalian limb covariation structure. Evolution. 2005:59(12):2691-704.

107. Bell E, Andres B, Goswami A. Integration and dissociation of limb elements in flying vertebrates: a comparison of pterosaurs, birds and bats. J Evol Biol. 2011;24(12):2586-99.

108. Eghbali H, Shahabi S, Najafi N, Mehdizadeh R, Yousefi S, Sharifi M. Postnatal growth, wing development and age estimations in the Mediterranean horseshoe bat Rhinolophus euryale (Chiroptera: Rhinolophidae) in Kerend cave, western Iran. Mammalia. 2018;82(3):276-87.

109. Klingenberg CP. Morphometric integration and modularity in configurations of landmarks: tools for evaluating a priori hypotheses. Evol Dev. 2009;11(4): 405-21.

110. Sears KE, Behringer RR, Rasweiler JJ, Niswander L. The evolutionary and developmental basis of parallel reduction in mammalian Zeugopod elements. Am Nat. 2007:169(1):105-17.

111. Giannini NP, Abdala F, Flores DA. Comparative postnatal ontogeny of the skull in Dromiciops gliroides (Marsupialia : Microbiotheriidae). Am Mus Novit. 2004;3460:1-17

112. Morris ZS, Vliet KA,Abzhanov A, Pierce SE. Heterochronicshifts and conserved embryonic shape underliecrocodylian craniofacial disparity andconvergence. Proc Biol Sci. 2019;286:20182389.

113. Jarrin VP, Flores C, Salcedo J. Morphological variation in the short-tailed fruit bat (Carollia) in Ecuador, with comments on the practical and philosophical aspects of boundaries among species. Integr Zool. 2010;5(3):226-40.

114. Swartz SM, Middleton KM. Biomechanics of the bat limb skeleton: scaling, material properties and mechanics. Cells Tissues Organs. 2008;187(1):59-84.

115. Jones PL, Page RA, Ratcliffe JM. To Scream or to Listen? Prey Detection and Discrimination in Animal-Eating Bats. In: Fenton M, Grinnell A, Popper A, Fay R, editors. Bat Bioacoustics. New York: Springer; 2016. p. 93-116.

116. Faure PA, Barclay RMR. Substrate-gleaning versus aerial-hawking - plasticity in the foraging and echolocation behavior of the long-eared bat, Myotis evotis. J Comp Physiol A. 1994;174(5):651-60.

117. Schulz M. Diet and foraging behavior of the golden-tipped bat, Kerivoula papuensis: a spider specialist? J Mammal. 2000;81(4):948-57.

118. Bahlman JW, Price-Waldman RM, Lippe HW, Breuer KS, Swartz SM. Simplifying a wing: diversity and functional consequences of digital joint reduction in bat wings. J Anat. 2016;229(1):114-27.

119. Cooper KL, Tabin CJ. Understanding of bat wing evolution takes flight. Genes Dev. 2008;22(2):121-4.
120. Giannini N, Goswami A, Sánchez-Villagra MR. Development of integumentary structures in Rousettus amplexicaudatus (Mammalia: Chiroptera: Pteropodidae) during late-embryonic and fetal stages. J Mammal. 2006:95(3):993-1001.

121. Goswami A, Binder WJ, Meachen J, O'Keefe FR. The fossil record of phenotypic integration and modularity: a deep-time perspective on developmental and evolutionary dynamics. Proc Natl Acad Sci U S A. 2015; 112(16):4891-6

122. Marroig G, Vivo M, Cheverud JM. Cranial evolution in sakis (Pithecia, Platyrrhini) II: evolutionary processes and morphological integration. J Evol Biol. 2003:17(1):144-55.

123. Marroig G, Shirai LT, Porto A, de Oliveira FB, De Conto V. The evolution of modularity in the mammalian skull II: evolutionary consequences. Evol Biol. 2009;36(1):136-48

124. Porto A, de Oliveira FB, Shirai LT, De Conto V, Marroig G. The evolution of modularity in the mammalian skull I: morphological integration patterns and magnitudes. Evol Biol. 2008:36(1):118-35.

125. Marroig G, Cheverud JM. Size as a line of least evolutionary resistance: DIET and adaptive morphological radiation in new world monkeys. Evolution. 2005:59(5):2005.
Ready to submit your research? Choose BMC and benefit from:

- fast, convenient online submission

- thorough peer review by experienced researchers in your field

- rapid publication on acceptance

- support for research data, including large and complex data types

- gold Open Access which fosters wider collaboration and increased citations

- maximum visibility for your research: over $100 \mathrm{M}$ website views per year

At BMC, research is always in progress.

Learn more biomedcentral.com/submissions 